\title{
Neurotoxicological characterization of fractionated polypeptide from the Sea Anemone Gyrostoma Helianthus on male albino rat
}

\author{
Mansour A. Al-Hazimi ${ }^{1,2}$, Gomma M.N. ${ }^{2}$, Waggas A.S. ${ }^{2}$ and Sayed M. Rawi ${ }^{2 \star}$ \\ ${ }^{1}$ Biological sciences department, Faculty of Sciences, King Abdulaziz University, Jeddah, 21589, Saudi Arabia \\ ${ }^{2}$ Faculty of Sciences and Arts, Khulais, King Abdulaziz University, Jeddah, 21589, Saudi Arabia \\ *Corresponding Author E-mail: rawisayed@yahoo.com
}

\author{
Publication Info \\ Paper received: \\ 01 March 2016 \\ Revised received: \\ 26 May 2016 \\ Re-revised received: \\ 22 August 2016 \\ Accepted: \\ 22 August 2016
}

\begin{abstract}
Marine organisms represent a valuable source of new compounds. The present study focused on the neurotoxicity of ethanolic crude extract and partially purified protein of Anemone species collected from the Red Sea shore of Jeddah, Saudia Arabia. The ethanolic extracts were found toxic to rats and the median lethal dose (LD50) was $20.3 \mathrm{mg} \mathrm{kg} \mathrm{b}$. wt. after IP of the crude extract. The rats showed behavioral changes such as tonic convulsions, paralysis and flexing of muscles. A single dose equal to $1 / 4$ LD50 administered IP, the crude extract induced differential and timedependentdopamine (DA), norepinephrine (NE), and serotonin (5-HT)neuronal neurotransmitter changes; reduced glutathione level $(\mathrm{P}<0.01)$ and highly affected cerebral histopathological disturbances. The crude extract and peptide fraction of $1 \mathrm{KDa}$ showed highest norepinephrine (P $<0.01)$ and dopamine $(\mathrm{P}<0.01)$ stimulatory activities. Whereas protein fraction of 500 Da resulted in maximal increase $(\mathrm{P}<0.01)$ in serotonin post 30 and $60 \mathrm{~min}$. In addition, the studied toxins vigorously affected rat brain cerebral cortex histological structure, the crude extract as well as the protein fraction of $1 \mathrm{KDa}$ disclosed the most histopathological effects. Light microscopy revealed neural hemorrhage, formation of pycnotic nuclei, marked edema due to enlargement of Virchow, congestion of blood vessels and focal hemorrhage.
\end{abstract}

Key words

Gyrostoma helianthus, Neurotoxicity; Monoamines, Histopathology

\section{Introduction}

The marine environment constitutes more than seventy percent of the world's surface and is home to diverse flora and fauna. The Red Sea is one of the most understudied areas in the world in terms of marine biodiversity. Among invertebrate animals, the Red Sea, home to 662 varieties of coral (Shima et al., 2010) which have developed a number of features that distinguish them from reefs found throughout most of the rest of this vast ocean area (Morel et al., 2010). However, among the most common type is G. helianthus which lives between the surface and $40 \mathrm{~m}$ depth and grows to a remarkable size (Akila and Jeyadoss, 2010). To date the versatility of sea anemones bioactive metabolites, including toxins have not been fully explored (Cheung et al., 2015). Till date, more than forty toxic peptides have been isolated from different species of sea anemone (Al-Hazmi et al., 2015), that are the source for treatment of many diseases such as cancer, AIDS, inflammatory condition, arthritis, malaria and several viral, bacterial and fungal diseases (Williams et al., 2007; Nazar etal., 2009).

The presence of toxic substances in sea anemones organisms has also been described as a common phenomenon. Till date more than 40 toxic peptides have been isolated from different types (Bellomio., 2009). They have cytotoxic, neurotoxic, cardiotoxic, nephrotoxic and hepatotoxic to internal systems (Ravindranet al., 2010; Ramkumaret al., 2012). Three classes of peptide toxins; 20$\mathrm{kDa}$ pore-forming cytolysins (Anderluhaet al., 2003), site-3 sodium channel toxins and Kv1 potassium channel toxins (Moran et al., 2009), have been well characterized. Of the 
three classes of toxins, both sodium and potassium channel peptide toxins have promising valuable pharmacological reagents. In other studies, sea anemone toxin, have found to provoke neurotransmitter release from synaptosomes (AlHazmi et al., 2015) and acting variably on the cholinesterase activity(Sudharsan et al., 2013). In light of the above, the present study was carried out to investigate the changes in dopamine, noradrenaline and serotonin neurotransmitters in the cerebral cortex in relation to cerebral histological alterations in rats administered with ethanolic crude extract and partially purified protein of anemone species.

\section{Materials and Methods}

Collection and preparation of crude extract: Live specimens of sea anemones ( $G$. helianthus) were collected, rapidly washed and weighed and finely ground for three minutes in absolute ethanol in a ratio of equal weight per volume. The blended material was centrifuged at 15,000 rpm, $27,000 \mathrm{~g}$ for $10 \mathrm{~min}$, at $4^{\circ} \mathrm{C}$, and the $1^{\text {st }}$ supernatant was preserved for further steps. Pellets were extracted for second time in absolute ethanol ( 2 nd supernatant $)$ and third extraction was done in $50 \%$ aqueous ethanol ( $3^{\text {rd }}$ supernatant). The three supernatants were added to each other and were then evaporated under reduced pressure at $40^{\circ} \mathrm{C}$ in a rotatory evaporator. Concentrated extracts were dried in a freeze dryer to obtain the final dried crude extract.

Isolation and partial purification of crude extract: Fractionation and purification of $G$. helianthusethanolic crude extract were carried out using Molecular Weight Exclusion Ultrafiltration: Crude extract of $G$. helianthus was filtered through membrane filters with cut off $3 \mathrm{kDa}, 1 \mathrm{kDa}$ and $500 \mathrm{Da}$ (76 $\mathrm{mm}$ in diameter, Millipore Corporation, Bedford, MA, USA). Ultrafiltration was performed under pressure in nitrogen gas $\left(40 \mathrm{Kg} \mathrm{cm}^{-2}\right)$.

Test animals: Adult male albino rats (Rattusrattus) (4-5) months old, 150-170 g body weight were obtained from the

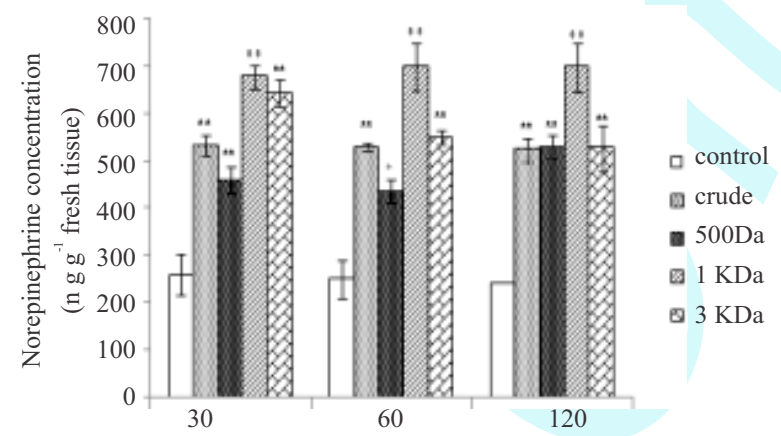

Fig. 1 : Effect of crude extract and fractioned proteins of sea anemone $G$. helianthus on norepinephrine concentration in rat brain cerebral cortex. Data are represented as Mean $\pm \mathrm{SE}$ of 6 rats.; \#Non significant; *Significant $P<0.05$; **Highly significant $P<0.01$ animal house of King Fahd Research at King Abdulaziz, Jeddah, Saudi Arabia. Animals were housed in stainless, steel cages ( 5 rats/cage) under controlled hygienic conditions at room temperature $\left(23 \pm 2{ }^{\circ} \mathrm{C}\right)$, relative humidity $(50 \pm 10 \%)$, and a photoperiod of $12 \mathrm{hr}$ for day and $12 \mathrm{hr}$ for night. The animals were fed with standard laboratory pelleted rodent food and drinking water, ad libitum, throughout the period of experimentation.

Experimental design and dose levels : After two weeks of acclimatization, male rats were divided into four groups as follows:

Group I : Rats in this group composed of six animals administered intraperitoneally with $0.5 \mathrm{ml}$ of saline solution served as control.

Group II : Composed of fifty animals, divided into 10 subgroups, each given crude extract intraperitoneally in saline at different doses $\left(5-50 \mathrm{mg} \mathrm{kg}^{-1}\right)$ and were used for $\mathrm{LD}_{50}$ determination after $24 \mathrm{hrs}$ following Litchfield and Wilcoxon (1949).

Group III : Rats were used to establish brain monoamine changes. The animals were divided into four subgroups each of 18 animals, injected intraperitoneally with one of the studied toxins (crude extract, $3 \mathrm{kDa}, 1 \mathrm{kDa}, 500 \mathrm{Da}$ ) in saline at a dose level of $5.08 \mathrm{mg} \mathrm{kg}^{-1}$ b.wt. which equivalent to $1 / 4$ $\mathrm{LD}_{50}$ crude extract.

Group IV : Animals were treated with crude extract or kDa, $1 \mathrm{kDa}$ or 500 Da partially purified protein, left for $24 \mathrm{hrs}$, and used for histopathological studies.

Biogenic monoamine determination: After 30, 60 and 120 min following, 6 animals of group 3 toxins administered with the studied toxins were sacrificed, brain cerebral cortex was carefully removed on ice and immediately applied for quantifying of monoamines levels following the method of

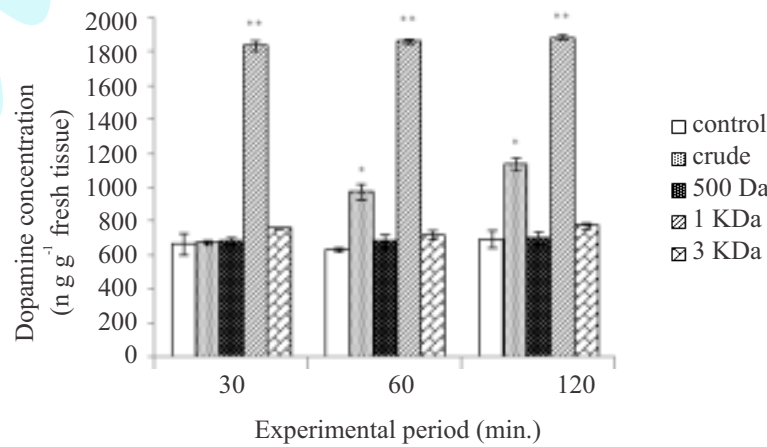

Fig. 2 : Effect of crude extract and fractioned proteins of sea anemone G. helianthus on dopamine concentration in rat brain cerebral cortex. Data are represented as Mean $\pm \mathrm{SE}$ of 6 rats. ; \# Non significant ; $*$ Significant $\mathrm{P}<$ $0.05 ; * *$ Highly significant $\mathrm{P}<0.01$ 


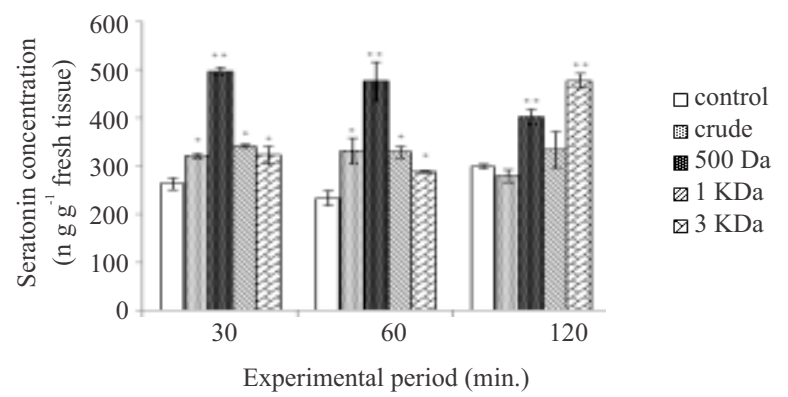

Fig. 3 : Effect of crude extract and fractioned proteins of the sea anemone $\mathrm{G}$. helianthus on serotonin concentration in rat brain cerebral cortex. Data are represented as Mean $\pm \mathrm{SE}$ of 6 rats. ; \# Non significant ; ${ }^{*}$ Significant $\mathrm{P}<$ $0.05 ; * *$ Highly significant $\mathrm{P}<0.01$

Glowinski and Iversen (1966). The samples were wiped dry with filter paper, weighed and then homogenized in $10 \mathrm{ml}$ volumes of $0.1 \mathrm{M}$ phosphate buffer ( $\mathrm{pH} 7.8$ ), using an ultrasonic homogenizer. The resulting homogenate was centrifuged at $10,000 \times \mathrm{g}$ for $60 \mathrm{~min}$ at $4^{\circ} \mathrm{C}$. The supernatant was collected and used to determine the level of serotonin, dopamine and norepinephrine following the method of Udenfriend and Wyngaarden (1956) as modified by Cliarlone (1978). The fluorescence activity of the tested samples was measured in a Jenway 6200 fluorometer.

Histopathological Examination : For light microscopic examination, rat cerebral cortex were dissected from rats of the $4^{\text {th }}$ group, divided into two equal halves. One half was fixed in $10 \%$ buffered formalin and embedded in paraffin. After a routine processing, paraffin sections of each tissue were cut into $5 \square \mu \mathrm{m}$ thickness, stained with haematoxylin and eosin and processed for histopathological observations (Luna, 1968).

Glutathione (G-SH) assay : Following decapitation, blood was collected in heparinized centrifuge tubes and plasma was separated by centrifugation and total glutathione peroxidase activity was measured according to the method of Paglia and Valentine's (1967) using Biodiagnostic GSH-px kit.

Statistical analysis : One-way ANOVA was used to analyze the results of biogenic monoamine and glutathione activity was analyzed by using SPSS v20program.

\section{Results and Discussion}

The toxicity of crude extract of $G$. helianthus sea anemone was investigated in male albino rats following intraperitoneal (i.p.) administration of different doses. After $24 \mathrm{hrs}$ of exposure, the $\mathrm{LC}_{50}$ was $20.5 \mathrm{mg} \mathrm{kg}^{-1}$. In comparison, it is important to remind that the crude extract of $G$.

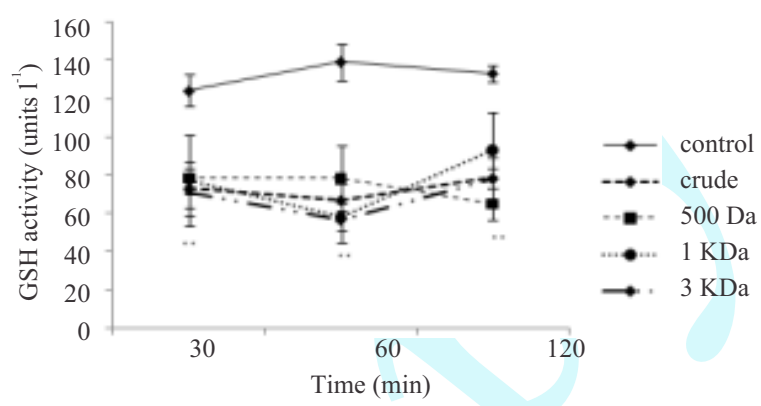

Fig. 4 : Effects of IP injection of G. helianthus crude extract and fractioned proteins at $1 / 4 \mathrm{LD} 50$ on serum glutathione (GSH) activity. Data are represented as Mean \pm SE of 6 rats. ;\# Non significant ;*Significant at $\mathrm{P}<0.05 ; * *$ Highly significant $\mathrm{P}<0.01$

helianthuson the basis of the calculated $\mathrm{LD}_{50}$ is highly toxic as compared with those recorded to another sea anemones species(Sanchez-Rodriguezet al., 2006; Sudharsan et al., 2013) These variations may be due to the differences in species and environmental conditions that may lead to differences in chemical compositions(Uris et al., 2011).

Immediately upon being injected with the crude extract, some rats exhibited labored respiration with occasional gasps and died within $10 \mathrm{~min}$, and brief coordinated convulsions occurred immediately before death. After treating with partially purified protein, intoxicated rats immediately showed more or less same behavioral pattern. Moreover, rats treated with $3 \mathrm{KDa}$ showed a fine tremor in fore and hind limbs. The behavior change are relatively consistent with the study of Sanchez-Rodriguez et al. (2006) and Sudharsan et al. (2013). Some behavioral changes like as flexing of muscles, tonic convulsions and paralysis might be due disturbances in neural signaling (Orts et al., 2013) or due to accumulation of neurotransmitters (Al-Hazmi et al., 2015) that are induced in response to toxic compounds. Frazãoet al. (2012) reported that around 250 toxic substances have been identified from different types of sea anemones, including toxins that affect voltage-gated $\mathrm{Na}^{+}$and $\mathrm{K}^{+}$channels and induce neurological behavioral disruption such as paralysis and convulsions. In the present investigation, instances of toxicity of various partially purified proteins, have been well established. However, 3Kd protein fraction exhibited higher neurotoxicity. Honma and Shiomi (2006), reported that, the cnidarians venom includes $3.5-6.5 \mathrm{kDa}$ voltage-gated sodium $\left(\mathrm{Na}_{\mathrm{v}}\right)$ and 3-5 kDa voltage-gated potassium $\left(\mathrm{K}_{\mathrm{v}}\right)$ channel

The present study also demonstrates an elevated level of cerebral cortex catecholamines in rats treated with a single dose of crude or partially purified protein of $G$ helianthus (Tables 1-3). Throughout the experiment, maximum and 

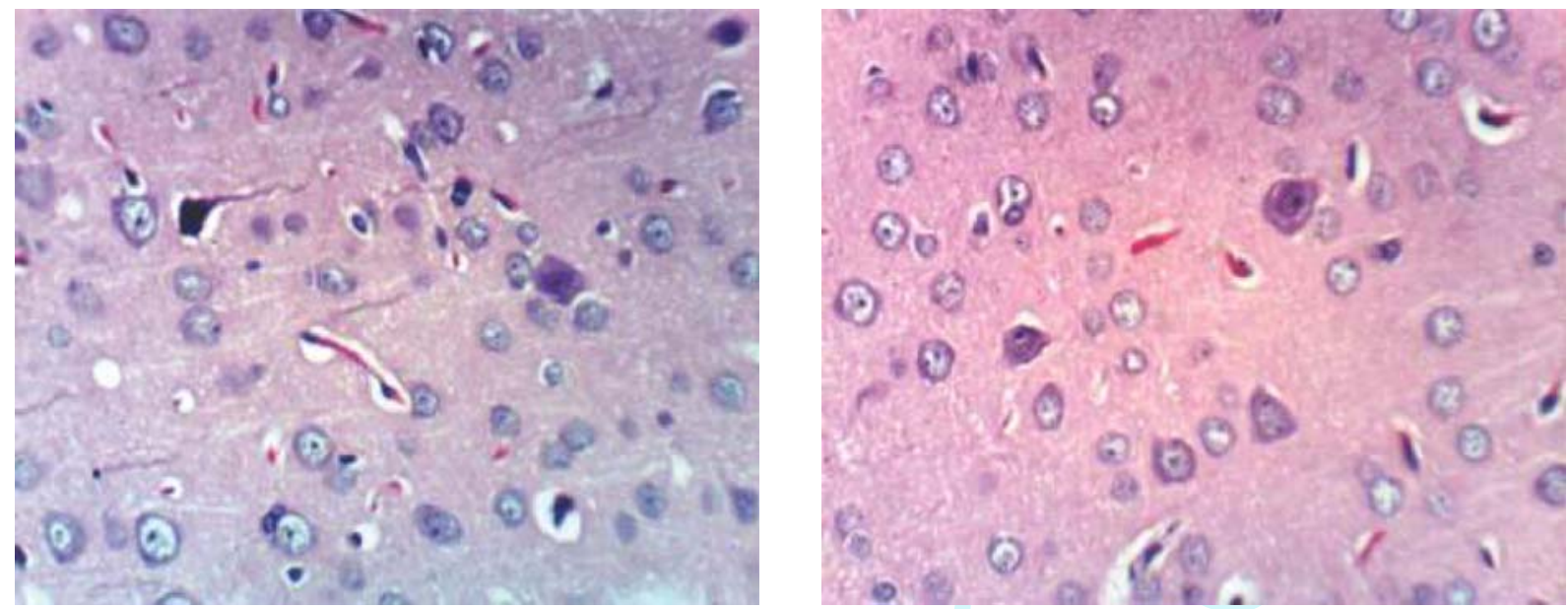

Fig. 5(A): Cerebral cortex of control rat group showing no histopathological changes[X 400]
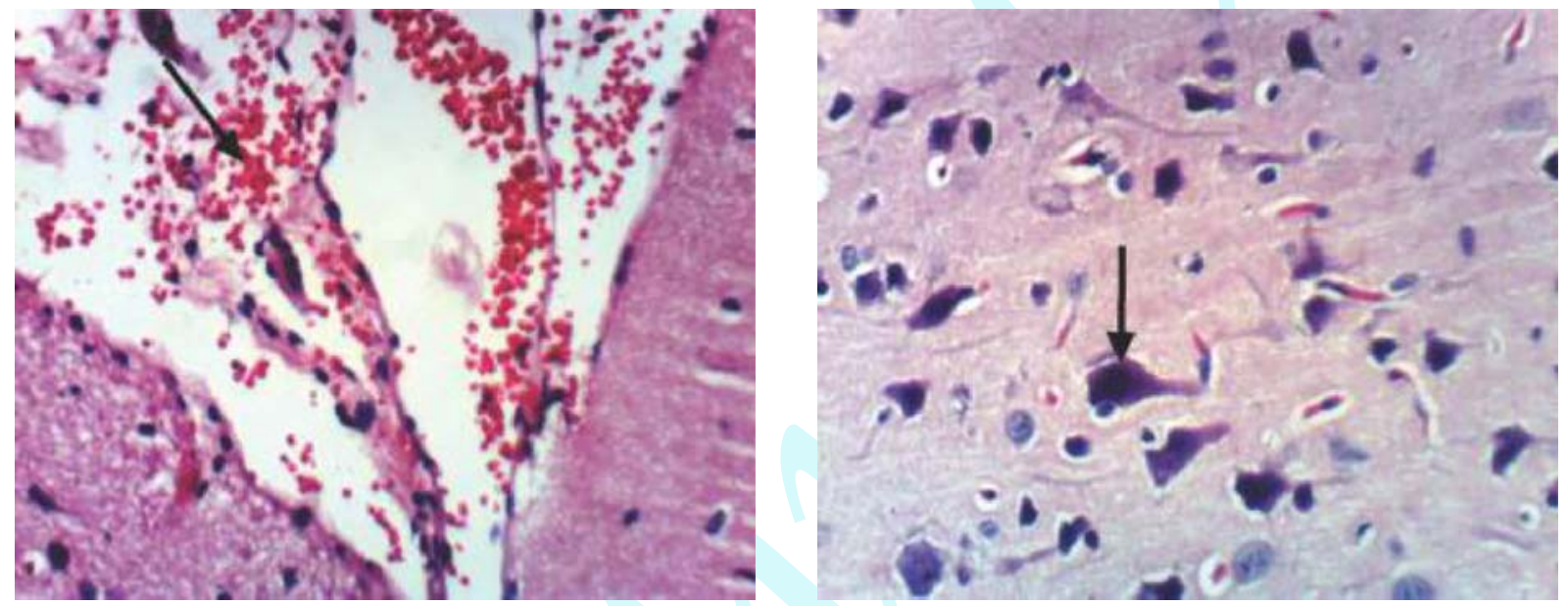

Fig. 5 (B) : Effect of crude extract of Sea Anemone G. helianthus on brain cerebral cortex of male albino rat showing, hemorrhage in the Virchow space (b), necrosis of neurons and neuronophagia (b) [X 400]

highly significant $(\mathrm{P}<0.01)$ effects of norepinephrine and dopamine were attained post treatment with fractioned protein of $1 \mathrm{KDa}$. In a parallel line with the previous context, serotonin, showed more or less same pattern elevated significant $(\mathrm{P}<0.01)$ effect with protein fraction of $500 \mathrm{Da}$. There has been much speculation about the cause of observed increase in monoamines level. Of particular concern is change in voltage gating channels which results in neuronal excitability and neurotransmitter release in sympathetic and parasympathetic ganglia (Cheng et al., 2010; Lazcano-Pérez et al., 2015), as well as inhibition of neural uptake of neurotransmitters as a result of inhibition of monoamine oxidase (MAO) (Cashman and Ghirmai ,2009), thus preventing the breakdown of monoamine neurotransmitters, and thereby increasing their availability. Overall, the results indicated of oxidative stress through inhibition of MAO activities and $\mathrm{H}_{2} \mathrm{O}_{2}$ levels, leading to neurotoxicity in rat brain.

In the present study, histopathology of control rat brain showed normal appearance (Fig. 5-A). On the other hand, rats exposed to G helianthus toxins for $24 \mathrm{hrs,} \mathrm{showed}$ areas of cellular infiltration, atrophy, pyknosis, necrosis, neurology, congestion of cerebral blood vessels, cellular and perivascular edema, as well as focal gliosis and focal cerebral hemorrhage (Fig. 5 B-E). The most prominent observation was caused due to protein fraction of $1 \mathrm{KDa}$. However, several studies have reported that marine toxins induce histopathlogical changes in the experimental animals. Mechaly et al. (2011) stated that toxins of Actinia fragacea 

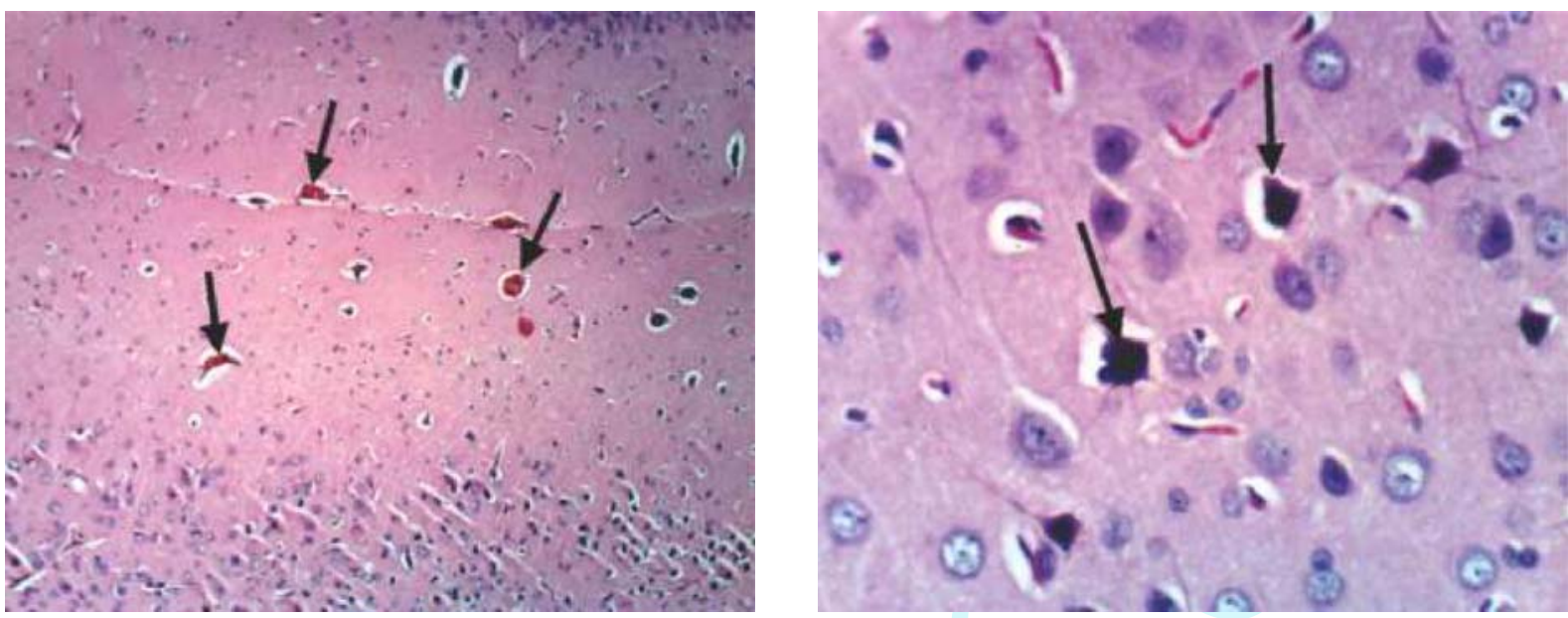

Fig. 5 (C) : Effect of 500 Da fractioned extract of Sea Anemone G. helianthus on brain cerebral cortex of male albino rat showing congestion of cerebral blood vessel (a) and necrosis of neurons (b). [X 400]
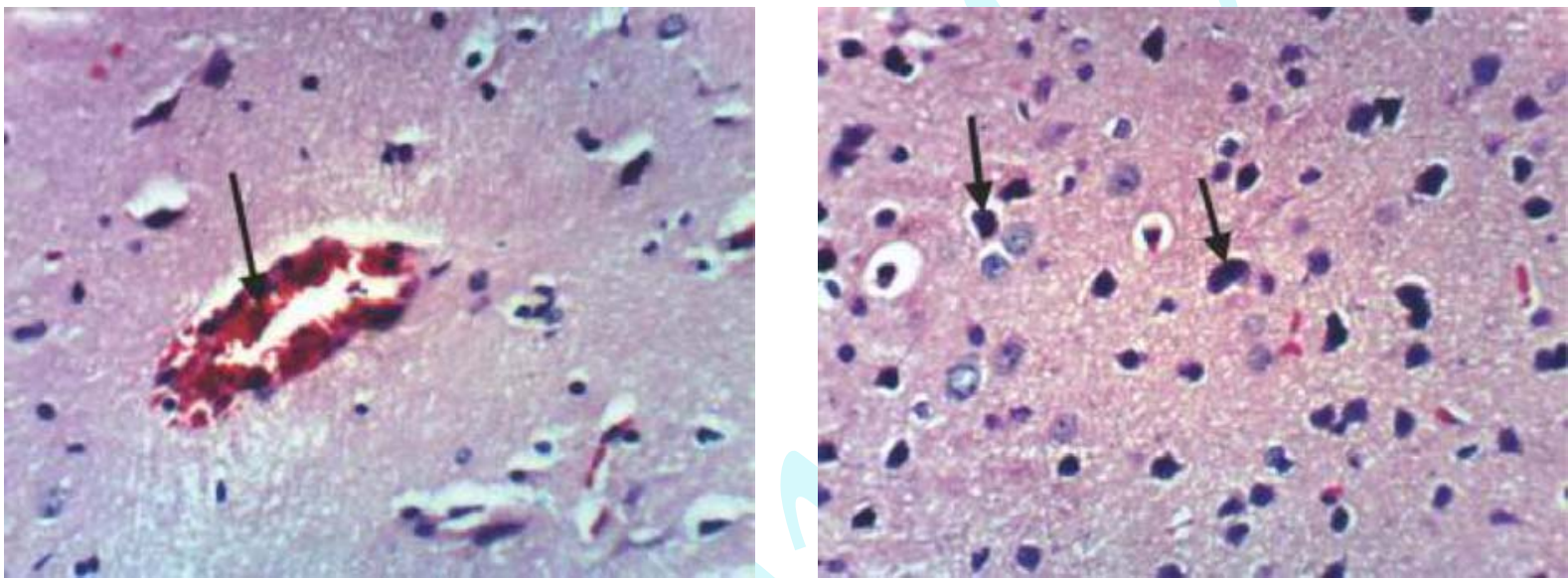

Fig. 5 (E) : Effect of 3KDa fractioned extract of Sea Anemone G. helianthus on brain cerebral cortex of male albino rat, showing congestion of cerebra blood capillaries (a), necrosis of neurons and neuronophagia (b) [X 400]
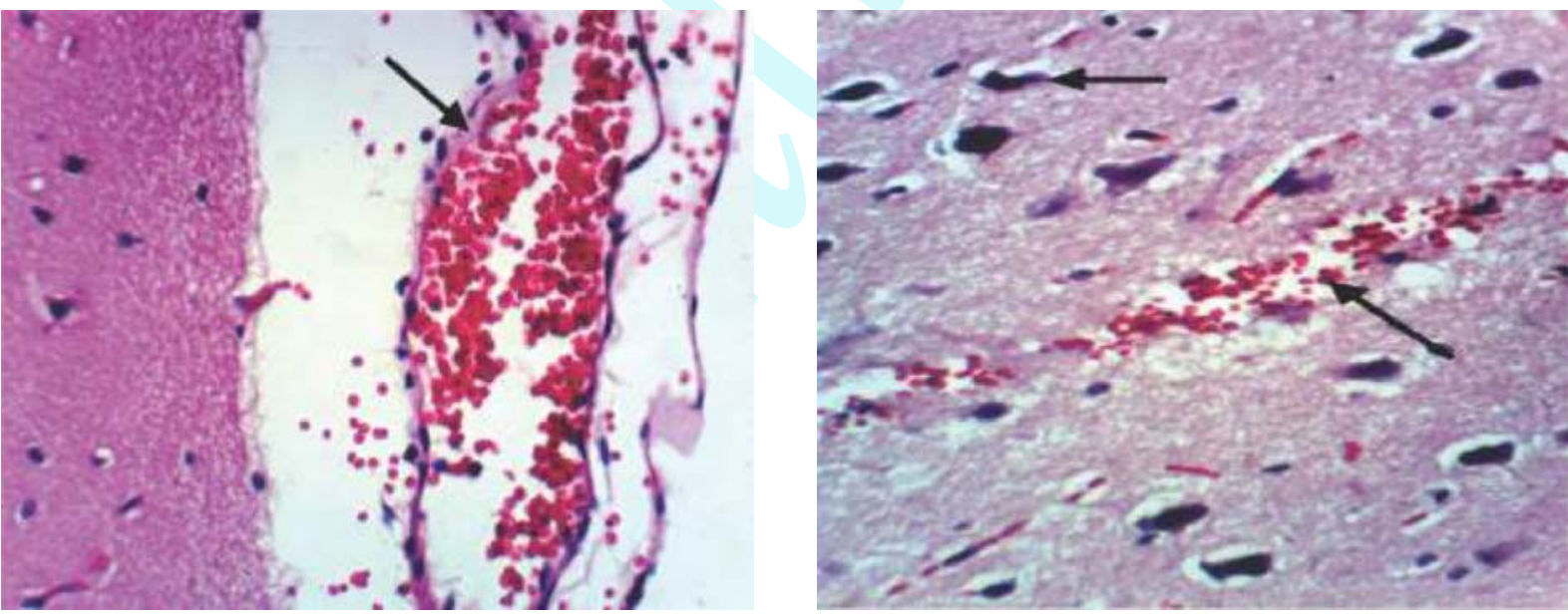

Fig. 5 (D) : Effect of 1KDa fractioned extract of Sea Anemone G.helianthus on brain cerebral cortex of male albino rat, showing focal hemorrhage (a, b), congestion in meningeal blood vessels, necrosis of neurons, and neuronophagia (b) [X 400] 
sea anemone toxins affects the permeability of target cells by forming pores in their plasma membranes. Moreover, Monroy-Estrada et al. (2013) suggested that sea anemone Bunodeopsis globulifera induced cytotoxicity through a different cellular mechanism that includes mitochondrial damage and alterations in the cell membrane. Histopathological changes can be explained by antioxidant changes. Reduced plasma glutathione (GSH) level was significantly $((\mathrm{P}<0.01)$ investigated in the present study (Fig.4). A correlation between biochemical and histological changes in brain tissues has been established, attributing the tissue and cell damages to the accumulation of hydrogen peroxide or production of other radicals (Sharma et al., 2014; Ayadi et al., 2015; Lalkovicova and Danielisova, 2016).

In conclusion, the results of the present study indicate the toxic effect of $G$. helianthus crude extracts and partially purified proteins in brain tissue that leads to behavioral disturbance, cerebral cortex neurotransmitter change and lead to oxidative stress. Additional studies are needed to fully detail the neurologic effects of individual sea anemone compounds.

\section{Acknowledgment}

This project was funded by the Deanship of Scientific Research (DSR) at King Abdulaziz University, Jeddah, under grant No. 163/130/1434). The authors, therefore, acknowledge with thanks DSR for technical and financial support.

\section{References}

Akila, N. and T. Jeyadoss: The potential of seaweed liquid fertilizer on the growth and antioxidant enhancement of Helianthus annuus. Orient J. Chem., 26, 1353-1360 (2010).

Al-Hazmi, M.A., M.N. Gomma, A.S. Waggas. and S.M. Rawi: Brain biogenic monoamines in relation to brain histopathology and plasma glutathione shuttle in rat after exposure to Sea Anemone Gyrostoma helianthus extract. Bioequiva. J. Bioequiv. Availab., 7, 005-011 (2015).

Anderluha G, P. Mačeka and H Jeremy: Lakeyb peeking into a secret world of pore-forming toxins: membrane binding processes studied by surface plasmon resonance. Toxicon., 42, 225-228 (2003).

AyadiI.,S. M.Monteiro,I.Regaya,A. Coimbra, F. Fernandes, M.M. Oliveira, F. Peixoto and W. Mnif: Biochemical and histological changes in the liver and gills of Nile tilapia Oreochromis niloticus exposed to Red 195 dye. $R S C A d v$., 5, 87168-87178

Bellomio, A., K. Morante, A. Barlic, I. Aguirre, A.R. Viguera and J.M. Gonza: Purification, cloning and characterization of ragacea toxin C, a novel actinoporin from the sea anemone Actinia fragacea. Toxicon., 54,869-880 (2009).

Cashman, J.R. and S. Ghirmai: Inhibition of serotonin and norepinephrine reuptake and inhibition of phosphodiesterase by multi-target inhibitors as potential agents for depression. Bioorg.. Med. Chem., 17, 6890-6897 (2009).
Cheng, A., A.L. Scott, B. Ladenheim, K. Chen, X. Ouyang, J.D. Lathia, M. Mughal, J.L. Cadet, M.P. Mattson and J.C. Shih: Monoamine oxidases regulate telencephalic neural progenitors in late embryonic and early postnatal development. J. Neurosci., 11, 10752-10762 (2010).

Cheung, R.C.F., T.B. Ng and J.H. Wong: Marine Peptides: Bioactivities and applications. Mar. Drugs, 13, 4006-4043 (2015).

Cliarlone, A.E.: Further modification of a fluorometric method for analyzing brain amines. Microchem. J., 23, 9-12 (1987).

Frazão B, V. Vasconcelos and A. Antunes: Sea Anemone (Cnidaria, Anthozoa, Actiniaria). Mar Drugs., 10, 1812-1851 (2012).

Glowinski, J. and L.L. Iversen: Regional studies of catecholamines in the rat brain. I. The disposition of $[3 \mathrm{H}]$ norepinephrine, $[3 \mathrm{H}]$ dopamine and [3H]DOPA in various regions of the brain. J. Neurochem., 13, 655-669 (1966).

Honma, T. and K. Shiomi: Peptide toxins in sea anemones: structural and functional aspects. Mar. Biotechnol., 8, 1-10 (2006)

Lalkovicová M. and V Danielisová:Neuroprotection and antioxidants. Neural Regen. Res., 11, 865-874 (2016).

Lazcano-Perez, F., U. Hernandez-Guzman and J Sanchez-Rodriguez: Cnidarian neurotoxic peptides affecting central nervous system targets. Cent. Nerv. Syst. Age. Med. Chem.,22 (2015).

Litchfield, J.T. and F.A. Jr., Wilcoxon: simplified method of evaluating dose effect experiments. J. Pharmacol. Exp. Ther., 96, 99-113 (1949).

Luna, L.G.: Manual of histology staining methods of the armed forces Institute of Pathology. $3^{\text {rd }}$ Edn., McGraw Hill Book Co., New York.(1968).

Mechaly A.E., A. Bellomio, D. Gil-Cartón, K. Morante and M. Valle:. Structural insights into the oligomerization and architecture of eukaryotic membrane pore-forming toxins. Structure, 19, 181-191 (2011).

Monroy-Estrada H.I., Y.I. Chirino,. I.E. Soria-Mercado and J. SánchezRodríguez: Toxins from the Caribbean Sea Anemone Bunodeopsis globulifera increase cisplatin-induced cytotoxicity of lung adenocarcinoma cells. J Venom Anim. Toxins. Incl. Trop. Dis., 19, 12 (2013).

Moran Y., G. Gordon and M. Gurevitz: Sea anemone toxins affecting voltage-gated sodium channels molecular and evolutionary features. Toxicon., 15, 10891101 (2009).

Morel, A., H. Claustre and B. Gentili: The most oligotrophic subtropical zones of the global ocean: similarities and differences in terms of chlorophyll and yellow substance. Biogeosciences, 7, 3139-3151 (2010).

Nazar, S.S., G. Ravikumar,. P. Williams, M.S. Ali and P. Suganthi: Screening of Indian coastal plant extracts for larvicidal activity of Culex quinquefaciatus. Ind. J. Sci. Technol., 2, 24-27 (2009).

Orts, D.J.B., S. Peigneur, B. Madio, J.S. Cassoli, G.G. Montandon, A.M.C. Pimenta, J.E. Bicudo,. J.C. Freitas, A.J. Zaharenko and J. Tytgat: Biochemical and electrophysiological characterization of two Sea Anemone Type 1 potassium toxins from a geographically distant population of Bunodosoma caissarum. Mar. Drugs, 11, 655-679 (2013).

Paglia, D.E. and W.N. Valentine: Studies on the quantitative and qualitative characterization of erythrocyte glutathione peroxidase. J. Lab. Clin. Med., 70,158-169 (1967).

Ramkumar, S., A.S. Sudhagar and K. Venkateshvaran: Bioactivity of venom extracted from the sea anemone Anthopleura asiatica (Cnidaria: Anthozoa): Toxicity and histopathological studies. 
I.J.F.A., 9, 71-76(2012).

Ravindran, V.S., L. Kannan and K. Venkateshvaran: Biological activity of sea anemone proteins: I. Toxicity and histopathology. Indian J. Exp. Biol., 48, 1225-1232 (2010).

Sanchez-Rodriguez, J., A. Zugasti, A. Santamaría, S. Galván-Arzate and L. Segura Puertas: Isolation, partial purification and characterization of active polypeptide from the sea anemone Bartholomea annulata. Basic Clin. Pharmacol. Toxicol., 99, 116121(2006).

Sharma, B., S. Singh and N.J. Siddiqi: Biomedical implications of heavy metals induced imbalances in redox systems. Biomed. Res. Int., 2014, 640754 (2014).

Shima, J.S., C.W. Osenberg and A.C. Stier: The vermetid gastropod Dendropoma maximum reduces coral growth and survival. Biol. Lett., 6, 815-818 (2010).

Sudharsan, S., P. Seedevi, U. Kanagarajan, R.S. Dalvi and S. Guptha:
Analgesic and neuromodulatory effects of sea anemone Stichodactylamertensii (brandt, 1835) methanolic extract from southeast coast of India. AJPP., 7, 2180-2200 (2013).

Udenfriend, S. and J.B. Wyngaarden: Precursors of adrenal epinephrine and norepinephrine in vivo. Biochim. Biophys. Acta., 20, 48-52 (1956).

Uris, R., L. Pedrera, D. Díaz, J.C. de Karam, T.P. Sudbrack, P.A. Valiente, D. Martínez, E.M. Cilli and F. Pazos: The membranotropic activity of $\mathrm{N}$-terminal peptides from the poreforming proteins sticholysin I and II is modulated by hydrophobic and electrostatic interactions as well as lipid composition. $J$. Biosci., 36, 781(2011).

Williams G.P., S. Babu, S. Ravikumar, K. Kathiresan, S.A. Prathap, S. Chinnapparaj, M.P. Marian and S.L. Alikhan: Antimicrobial activity of tissue and associated bacteria from benthic sea anemone Stichodactyl ahaddoni against microbial pathogens. J. Environ. Biol., 28, 789-793 (2007). 